\title{
PAPER TAPE DATA ACQUISITION SYSTEM
}

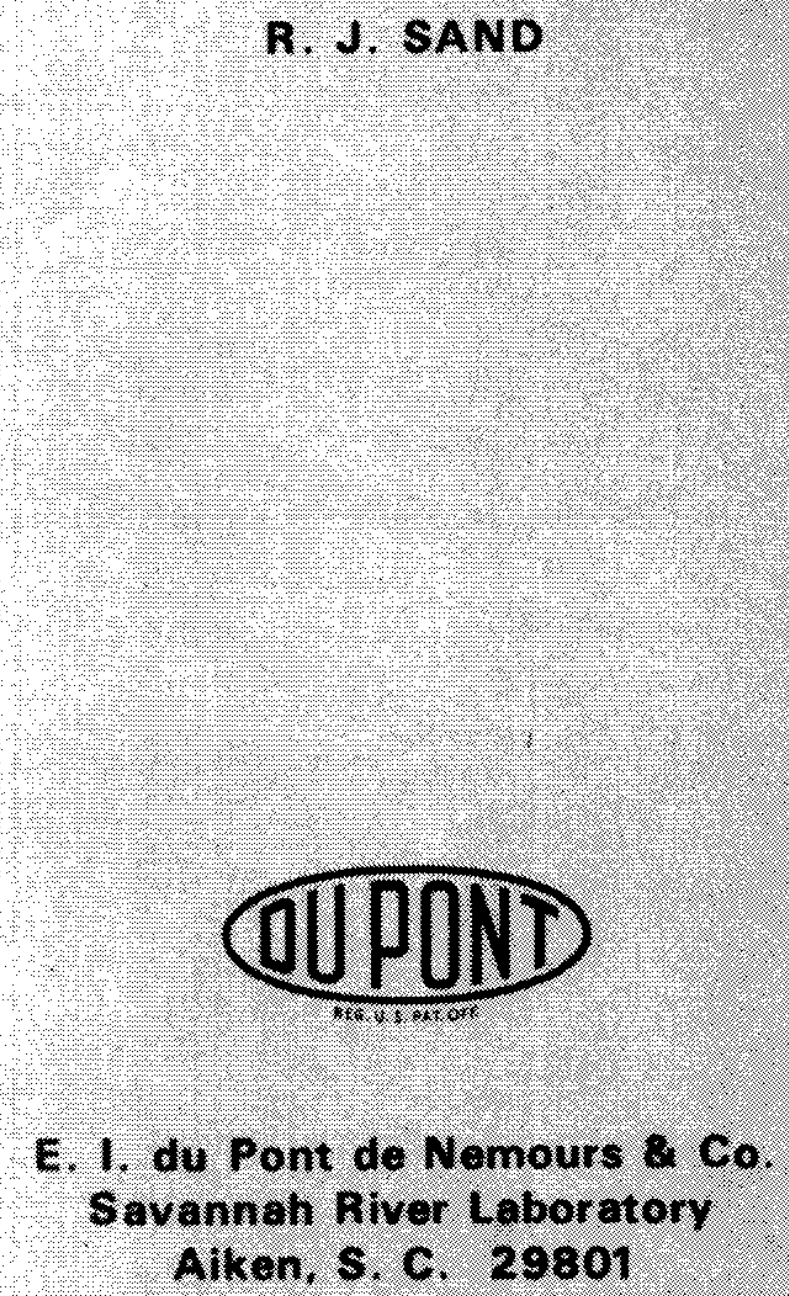

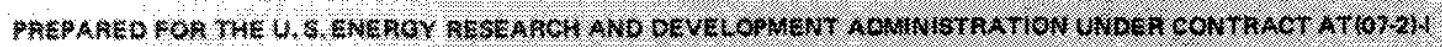




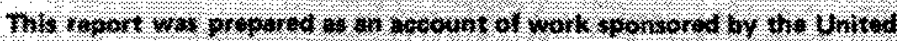

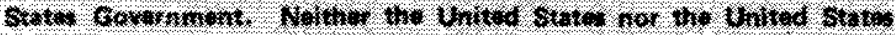

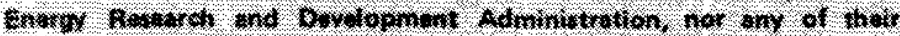

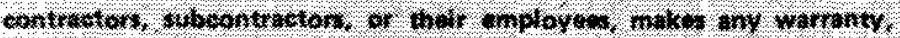

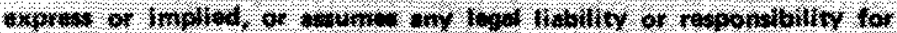

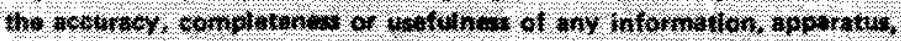

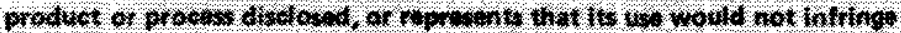

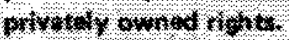

\section{Priktad th the Ghited stutes of Amerted} Avattalste from

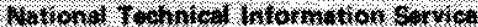

U. 5 . Deptert thent of commeres

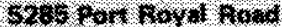
Springhide, Viomin 22160

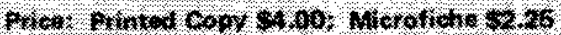




\title{
PAPER TAPE DATA ACQUISITION SYSTEM
}

\author{
by \\ R. J. Sand \\ Approved by \\ D. E. Waters, Research Manager \\ Laboratory Operations and Services Division
}

May 1975

E. 1. du Pont de Nemours \& Co. Savannah Fiver Laboratory

Aiken, S. C. 29801

PREPAREO FOR THE U.S. ENERGY AESEARCH ANO DEVELOFMENT ADMINISTRATION UNDER CONTRACT AT(O7-2)-3 


\section{ABSTRACT}

A system was developed to store chemical analysis data from scientific instruments. The data acquisition system stores, in dynamic memory, analog signals received from one to eight data channels. The channels are sampled at rates from $0.0025 \mathrm{~Hz}$ to $20 \mathrm{kHz}$. Data are later transferred to paper tape for subsequent analysis in a minicomputer. 


\section{CONTENTS}

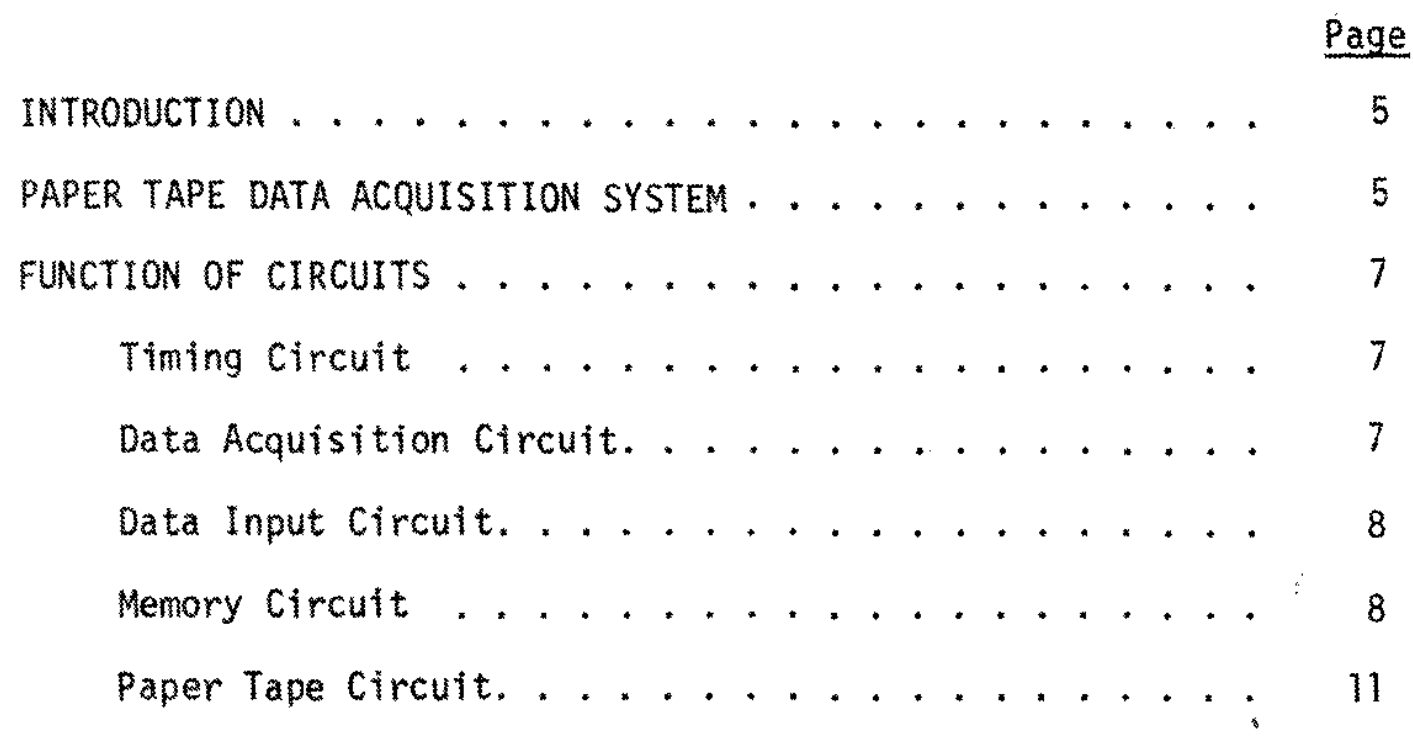

\section{LIST OF FIGURES}

No. Page

1. Logic Flow Chart..................... 6

2. Specimen of 8-Bit Paper Tape .............. 7

3. Logic Frame (Front View) . . . . . . . . . . . . 9

4. Logic Frame (Rear View) ............. 10

5. Start-Stop Input TTL Wave Forms. . . . . . . . . . . 11 


\section{PAPER TAPE DATA ACQUISITION SYSTEM}

\section{INTRODUCTION}

A method was needed to record analog electrochemical instrument data for subsequent processing by minicomputer analysis programs. A wide range of data acquisition rates was required. Also desirable was the ability to sample various combinations of different input signals.

Basic equipment existed for data sampling, for rapid storage of data obtained at high rates, and for punching data on paper tape at low rates. Control electronics were designed and combined with existing equipment to produce a versatile data acquisition system. This system gathers data from any analog electrical signal at the presently avadiable rates.

\section{PAPER TAPE DATA ACQUISITION SYSTEM}

The paper tape data acquisition system can sample up to eight and $\log$ channels at up to $20 \mathrm{kHz}$ and can store data for as many as 512 samples in memory for later transfer to punched paper tape. The system uses a DateZ DAS-16 multiplexing analog-tomdigital converter (Datel Systems, Inc., Canton, Massachusetts), which may be expanded to 16 analog inputs by adding a few plug-in modules. A RAMN 1024 charge storage memory (Standard Logic, Inc., Santa Ana, Califomia) arranged for use as a $1024 \times 8$ bit data storage unit holds information until a paper tape is punched. The motorized paper tape punch (Model 2, Friden, Inc., San Leandro, California) can punch frames at $16.667 \mathrm{~Hz}$.

The control circuitry to interface the three major components is prinarily transistor-transistor logic (TTL) integrated circuits running on a $20 \mathrm{kHz}$ systen clock signal genexated from a $2 \mathrm{MHz}$ crystal oscillator (Figure 1). Gating circuitry and front panel rotary switches permit data sampling at rates from $0.0025 \mathrm{~Hz}$ to $20 \mathrm{kHz}$, i.e., once every $400 \mathrm{sec}$ to 50 usec. The DAS-16 unit digitizes $\$ 10-V$ analog signals to $12 \mathrm{mit}$ resolution. The $12 \mathrm{-bit}$ words are split into two groups of six bits each to permit storage in two $8 \mathrm{mbit}$ word locations in the memory and similarily on 8 -bit paper tape (Figure 2). The paper tape bit arrangement uses one bit (No. 8) to indicate to the data analysis equipment the presence of data on the tape. The No. 7 bit distinguishes the most significant six bits from the least significant six bits, Bit Nos. 1-6 are the data bits themselves. 




FIGURE 1. Logic Flow Chart 


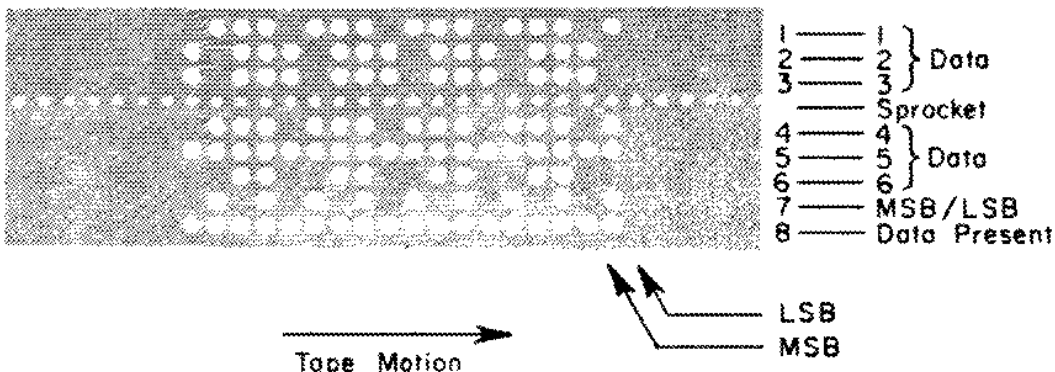

FIGURE 2. Specimen of 8-Bit Paper Tape

Existing teletype paper tape readers have data bit designations and sprocket holes exactly reversed from the Friden punch. Data tape may be simply turned face down and read into the teletype to facilitate data analysis.

Data are stored in the memory identically to the paper tape format. Depending on how many signals are sampled, data points range from a maximum of 512 per channel for one channel to 64 per channel when sampling all 8 inputs. The analog-to-digital converter (ADC) digitizes to \pm 1.0 bit out of 2048 with a signal resolution of $9.8 \mathrm{mV}$ per bit.

\section{FUNCTION OF CIRCUITS}

\section{Timing Circult}

The system clock, derived from a $2 \mathrm{MHz}$ crystal oscillator, runs at $20 \mathrm{kHz}$. This rate was chosen because each menory system plane must be refreshed at least once every $2 \mathrm{msec}$. The internal arrangenent of storage and refresh cixcuitry refreshes the $32 \times 32 \times 8$ matrix of storage cells at one plane of $32 \times 8$ cells at a time. Therefore, refresh clock pulses theoretically must occur at least once every 62.5 usec; in this systen refresh pulses occur once every 50 usec. The "memory refresh" cycle is required because the storage cells use interelement capacitance of the metal oxide semiconductor (MOS) and field effect transistor (FET) cell array to maintain the high or low state charge. The data storage charge decays with time, thus inferring a "dynami c" memory.

\section{Data Acquisition Circuit}

The "data-acquire" button (a magnetic field effect, solid state device) and the devicemselect flip-flop circuit enable the sample 
rate clock count-down circuits and the DAS-16, and set the DAS-16 converter to-memory buffer to divide the 12-bit data word into two 8-bit words for storage in the memory. The device-select flip-flop circuit also initiates the memory write controls and disables the punch output buffer.

The acquisition of data can be stopped at any time by dem pressing the "stop data acquire" button. This action latches in the last memory location used and disables the DAS-16 "strobe and device select."

Remote start-stop inputs on the front pane1, a modification to photographed equipment (Figures 3 and 4 ), allow external commands to start and stop the "data-acquire" mode at times synchronized with outside events. Pulsed operation or level change operation from equipment to be monitored is possible (Figure 5).

\section{Data Input Circuit}

The DAS-16 module is fixed in the "sequential-sample" mode but may be changed by the front panel control to short cycle the input channels starting at Channel 0 and ending with any of the 16 available channels (Channels $0-7$ operational). The front panel display of the DAS-16 indicates the channel number and the digitized value of the analog sample. The DAS-16 analog inputs (on the input panel at the rear of the rack) accept $\pm 10-V$ inputs applied directly to the DAS -16 connectors. The rate at which the DAS-16 can sample data is any combination of the significant digits $2.5,5,10$, or 20 and multipliers $10^{-3}, 10^{-2}, 10^{-1}, 10^{0}, 10^{1}, 10^{2}$, or $10^{3} \mathrm{~Hz}$. This provides the desired frequency of 3 -usec strobe pulses to the DAS -16 .

\section{Memory Circuit}

The memory receives "initiate" and "write" commands at the conclusion of the DAS 16 analog-to-digital conversion cycle. Since the single 12-bit data word must be stored in two menory words, circuitry must provide for memory address incrementation and memory initiate and write commands from two sources. The DAS-16 begins the sequence, and then the last half of the data word is brought in by the memory. At the conclusion of this operation, the "memory address" flip-flop, the memory "initiate" and "write" flip-flops, and the "data word divider" flip-flop are retumed to their "new data word" state to awat information from the DAS-16. 


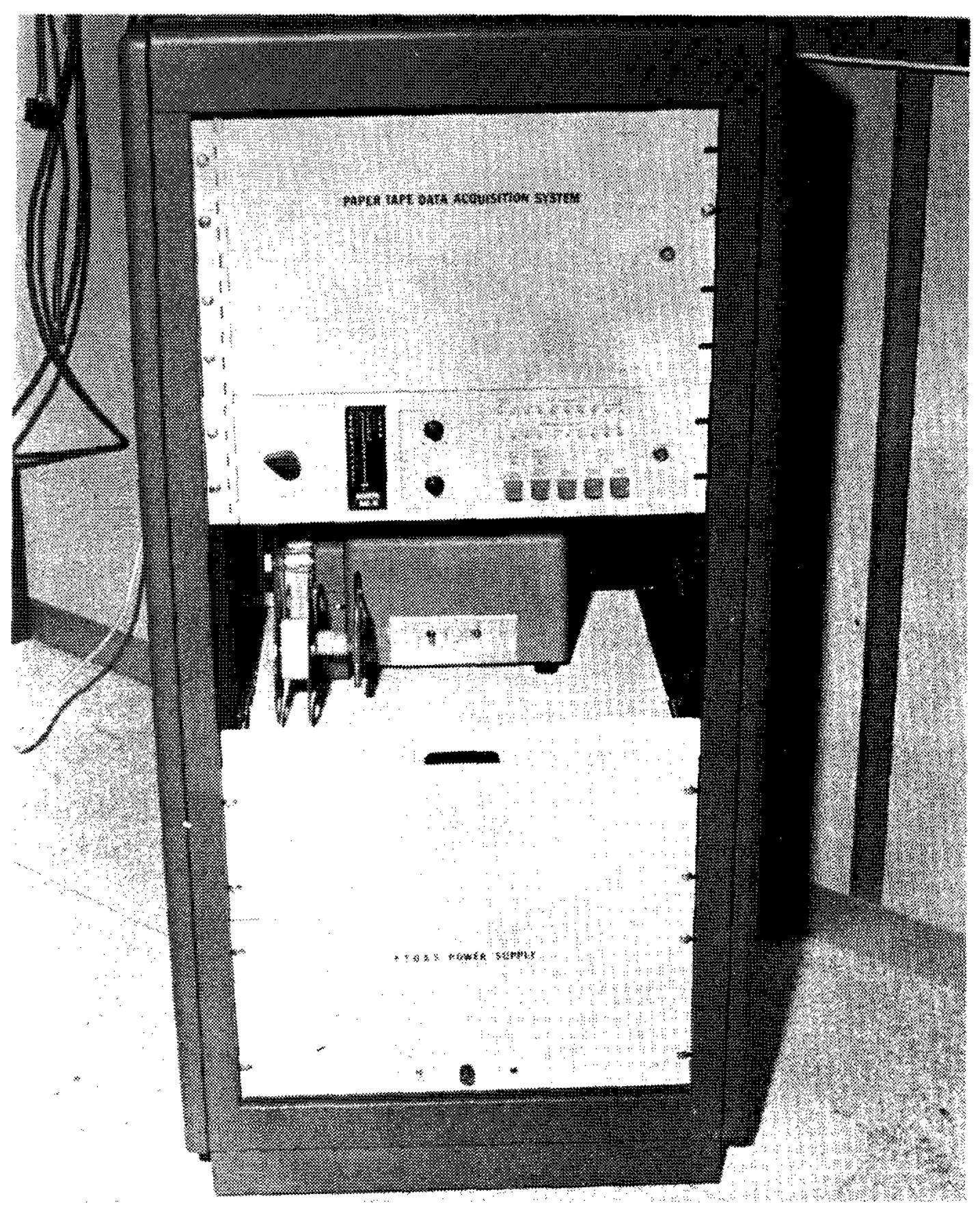

FIGURE 3. Logic Frame (Front View) 


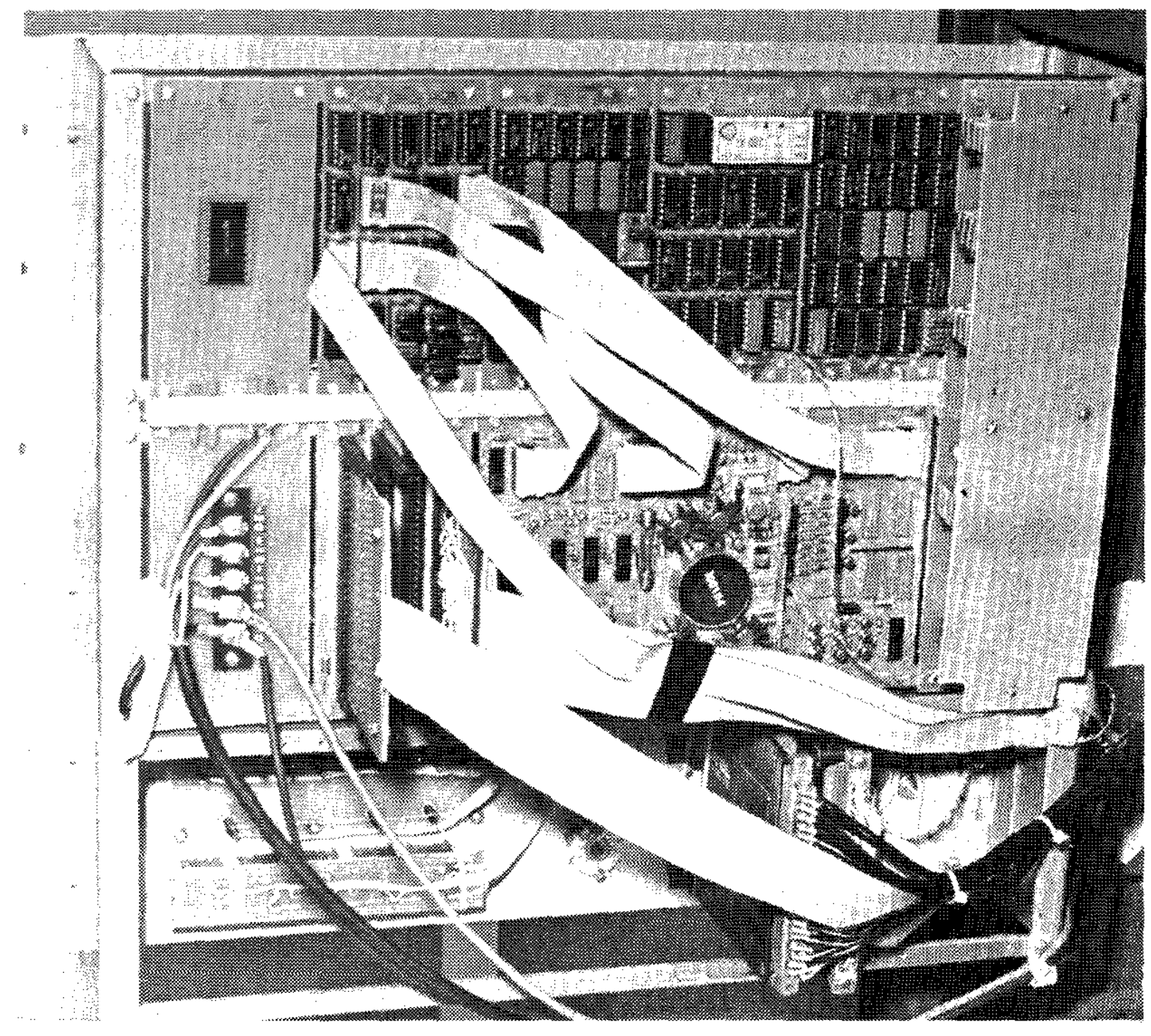

FIGURE 4. Logic Frame (Rear View) 


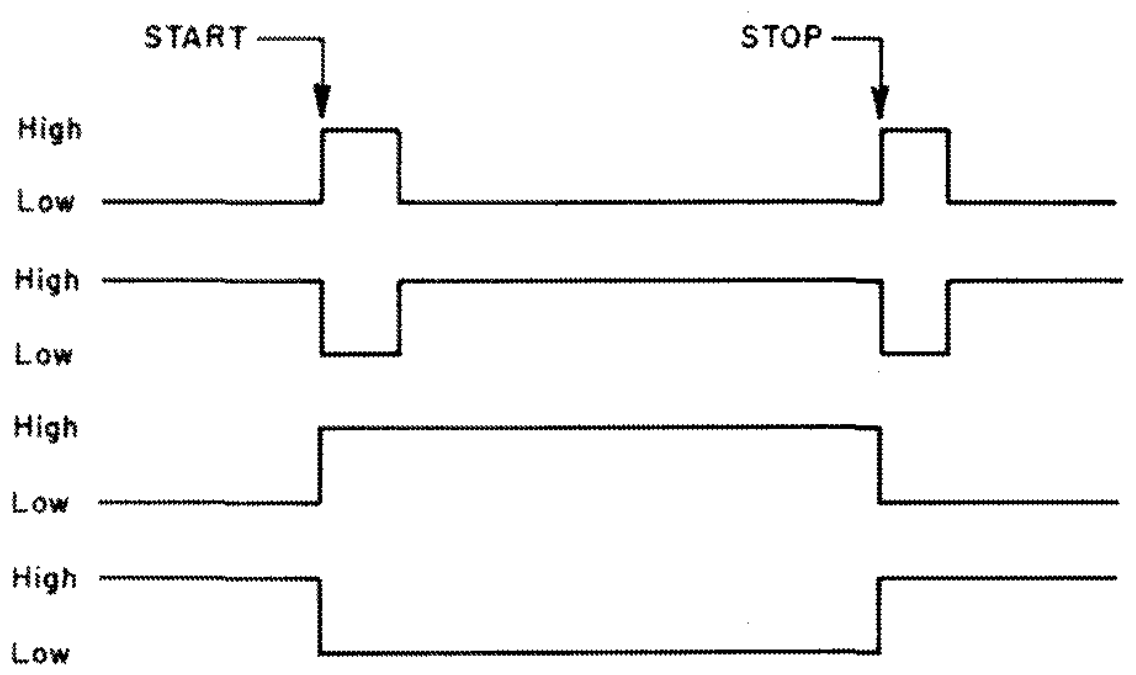

FIGURE 5. Start-Stop Input TTL Wave Forms

Provided in the equipment is a monitor to automatically end the data run when the memory is filled, thereby preventing exadication of previously gathered data. At this point, data will remain in the menory until new data are stored by the start of a new run or until power is lost to the instrument.

\section{Paper Tape Circuit}

paper tape may be punched at the operator's convenience and may also be repunched should the paper tape punch fail, preventing data loss after the test is completed. The paper tape is punched after first preparing the equipment by resetting the punch. This initiates the last location flip-flop and the paper tape word flipflop. By depressing the "tape feed" button, paper tape leader is generated containing only sprocket holes. After sufficient leader is obtained, the "tape feed" button should be released. When the "start punch" button is depressed, the punch will begin to cycle, reading from memory and punching tape until the information contained in the menory at the last location is on tape. When the punch stops, depressing the "tape feed" button will add trailer to the tape to complete the operation.

The Eriden paper tape punch is interfaced to the menory through infraxed optical couplers. The punch and clutch coils are powered by 135 vDC switched by high voltage power transistors. Diode spike suppressors are installed inside the punch across each coi1. Extemal line noise suppression is provided by a $500 \mathrm{~W}$ isolation transformer mounted at the lower rear of the rack. 